\title{
Multicolor chromosome bar codes
}

\author{
S. Müller ${ }^{a} \quad J . W^{2}$ ienberg ${ }^{a, b}$ \\ ${ }^{a}$ Institute for Anthropology and Human Genetics, Department of Biology II, Ludwig-Maximilians-University, \\ Munich and ${ }^{\mathrm{b}} \mathrm{Chrombios} \mathrm{GmbH}$, Raubling (Germany)
}

Manuscript received 30 November 2005; accepted in revised form for publication by T. Liehr, 3 April 2006.

\begin{abstract}
Chromosome bar codes are multicolor banding patterns produced by fluorescence in situ hybridization (FISH) with differentially labeled and pooled sub-regional DNA probes. These molecular cytogenetic tools facilitate chromosome identification and the delineation of both inter- and intra-chromosomal rearrangements. We present an overview of the various conceptual approaches which can
\end{abstract}

be largely divided into two classes: Simple bar codes designed for chromosome identification and complex bar codes for high resolution aberration screening of entire karyotypes. We address the issue of color redundancy and how to overcome this limitation by complementation of bar codes with whole chromosome painting probes.

Copyright (c) 2006 S. Karger AG, Basel
Currently, a standard technique to screen for chromosomal rearrangements is color karyotyping by multicolor fluorescence in situ hybridization (FISH) of combinatorially labeled probes specific for entire chromosomes (MFISH or spectral karyotyping; SKY) (Schröck et al., 1996; Speicher et al., 1996). The same goal can be achieved using less fluorophores, when paint probes are labeled in different color combinations and ratios (COBRA, COmbined Binary RAtio labeling) (Tanke et al., 1999). Chromosome painting with chromosome specific probes, however, only allows the identification of whole chromosomes and therefore is limited mainly to the analysis of translocations. Since this technique provides no further differentiation of chromosomal sub-regions, intra-chromosomal rearrangements such as inversions often escape detection. A more detailed definition of the chromosomal breakpoints involved in rearrangements within a chromosome relies on the banding pattern produced by the chromosomal counterstain or requires additional FISH experiments with sub-regional DNA probes.

Request reprints from Stefan Müller

Anthropology and Human Genetics, Department of Biology II

Ludwig-Maximilians-University

Großhaderner Strasse 2

DE-82152 Planegg-Martinsried (Germany)

telephone: +49 89 21806728; fax: +49 8921806719

e-mail: s.mueller@lrz.uni-muenchen.de
To address this issue, so called chromosome bar codes were introduced to define chromosomes and chromosome bands on the basis of their DNA content rather than gray scale banding patterns as used in classical cytogenetics. Chromosome bar codes are multicolor banding patterns produced by fluorescence in situ hybridization (FISH) with differentially labeled and pooled subregional DNA probes (Ried et al., 1992). They can be used as a molecular cytogenetic tool to facilitate chromosome identification and for the characterization of both inter- and intra-chromosomal rearrangements. Bar codes can be designed for individual chromosomes (Ried et al., 1992), for subsets of chromosomes or for the entire chromosome complement (Lengauer et al., 1993). A multicolor banding pattern can be composed of at least two and up to seven different colors, depending on the microscopic setup available. Compared to classical banding patterns such as G-banding, bar codes have numerous advantages: (i) the bar code pattern is DNA based and not based on classical chromosome banding patterns. Thus, recent genome sequencing information can directly be correlated with chromosome morphology; (ii) bar codes can be specifically designed by choosing appropriate DNA probes to produce any desired pattern and finally (iii) each additional color multiplies the banding information and therefore the resolution of the pattern. The resolution of the banding pattern depends on the size of the DNA probes chosen and the physical mapping distance between individual probes along a chromosome. Consequently, the spa- 
tial resolution can vary from some few hundred base pairs in hybridization experiments on extended chromatin fibers up to some Mbp when hybridizing to fully condensed metaphase chromosomes.

\section{Bar codes for chromosome identification}

Depending on the application, different conceptual approaches can be taken. In case the primary aim is to identify chromosomes, the pattern produced by the chromosome bar code probe can be as simple as possible in order to be cost efficient. For human chromosome identification, a series of differentially labeled yeast artificial chromosome (YAC) clones was used to produce a unique color code for each chromosome, further taking into account the relative mapping position of the probes on the respective chromosome (Lengauer et al., 1993). More recently, combinatorially labeled alphoid DNA probes have been used as molecular tags, identifying each human centromere in a single experiment (Henegariu et al., 2001a; Nietzel et al., 2001). Alternatively, DNA probes containing inter-chromosomal segmental duplications (Low Copy Repeats) can be used to produce molecular tags. With this approach, approximately 40 bars per haploid chromosome set can be obtained using only three differentially labeled bacterial artificial chromosome (BAC) clones (Fig. 1A). Possibly more important are chromosome bar codes for mouse chromosome identification. The karyotype of the mouse is composed of acrocentric chromosomes, many of which are of similar size and banding pattern. Henegariu et al. (2001b) developed a triple color multiplex probe composed of BAC clones which drastically simplifies chromosome identification and may be useful for physical mapping purposes.

\section{High-resolution bar codes for single chromosomes}

In a case where a single chromosome should be analyzed in more detail a high-resolution chromosome bar code specific for the targeted chromosome can be applied. For this purpose, vector cloned probes are frequently used as first described for a set of seven cosmid clones (Ried et al., 1992). Figure $1 \mathrm{~B}$ illustrates the use of combinatorially labeled YAC clones to delineate rearrangements of chromosome 3 in a cervix carcinoma cell line (HeLa). Another approach that was named Multi Color Banding (MCB; Chudoba et al., 1999) used sub-regional painting probes established by micro-dissection of chromosome segments of various sizes to colorize bands on individual chromosomes.

\section{Bar codes for whole karyotype aberration screening}

Maximum resolution across the entire chromosome complement in a single FISH experiment is a prerequisite for efficient screening of entire karyotypes for unknown inter- and intra-chromosomal rearrangements. To date, three different FISH based strategies for the simultaneous differentiation of the entire human karyotype have been proposed: (i) a two color bar code based on a set of Alu-PCR products from 11 'fragmented somatic cell hybrids' (Müller et al., 1997); (ii) a three color bar code, termed 'cross-species color segmenting' or Rx-FISH, composed of gibbon chromosome specific painting probes (Müller et al., 1998). Since the karyotypes of gibbons (hominoid primates) are highly rearranged compared to humans by multiple translocations, whole chromosome painting probes from these species can delineate up to 90 different chromosome segments in the human karyotype. Probe sets developed for the approaches described in (i) and (ii) were more recently combined, resulting in approximately 160 positive stained bands per haploid chromosome set and yielding a resolution equal to approximately 400 G-bands (Müller and Wienberg, 2000). (iii) Recently, a resolution of up to the 800 band level was obtained when the 138 available region-specific microdissection derived probes of the above mentioned $\mathrm{MCB}$ probe set were pooled to form a five-fluor multiplex probe covering all human chromosomes (Weise et al., 2003).

Chromosome bar codes can potentially be applied in various fields of cytogenetic research, ranging from clinical cytogenetics, mutation research to comparative genome analysis. However, they were particularly useful for the detection of tumor-specific chromosomal aberrations and of chromosome rearrangements that occurred during primate evolution. RxFISH has successfully been used to screen solid tumors (Micci et al., 1999; Kim et al., 2001) and haematological malignancies (Espinet et al., 2000; Harrison et al., 2000, 2001; Sole et al., 2001). In all cases previously unidentified intra- as well as inter-chromosomal rearrangements were detected, thus demonstrating the potential of this approach for the accurate characterization of complex rearrangements with subtle abnormalities. The Rx-FISH probe set and the bar code probe derived from 'fragmented hy-

Fig. 1. (A) Basic bar code designed to assist in human chromosome identification. It is comprised of three differentially labeled BAC clones (RP11-413E6 green, RP11-339F13 blue and RP11-740N7 red) containing inter-chromosomal segmental duplications and producing approximately 40 bars per haploid chromosome set. (B) FISH of six combinatorially labeled CEPH YAC clones (852b3 blue, $938 \mathrm{~g} 11$ magenta, $808 \mathrm{~b} 10$ red, $929 \mathrm{~g} 8$ green, $806 \mathrm{c} 12$ turquoise, $866 \mathrm{e} 7$ yellow) results in a bar code specific for chromosome 3 , by which one normal chromosome 3 and four derivatives with different breakpoints were detected in a cervix carcinoma cell line (HeLa). (C-J) A non redundant chromosome bar code probe hybridized to (C-F) a human constitutional disorder $(46, \mathrm{XX}, \mathrm{t}(1 ; 8)(\mathrm{p} 36 ; \mathrm{p} 11.2))$ and to $(\mathbf{G}-\mathbf{J})$ Bonobo metaphases: the threefluor bar code probe in $(\mathbf{C})$ and $(\mathbf{G})$ is complemented by a four-fluor labeled set of human whole chromosome painting probes, depicted in $(\mathbf{D}, \mathbf{E})$ and $(\mathbf{H}, \mathbf{I})$, respectively. (F) Normal (top row) and derivative (bottom) chromosomes 1 and 8 of the $t(1 ; 8)$ case. (J) Alignment of human (left) and Bonobo (right) chromosome 2, 4, 5, 7, 9, 12, 15, 17 and 18 homologs which differ by a fusion and inversions. (K) Co-hybridization of a chromosome 6 paint probe (green) with a 6 pter $10 \mathrm{Mbp}$ pool of tiling path BAC clones. 


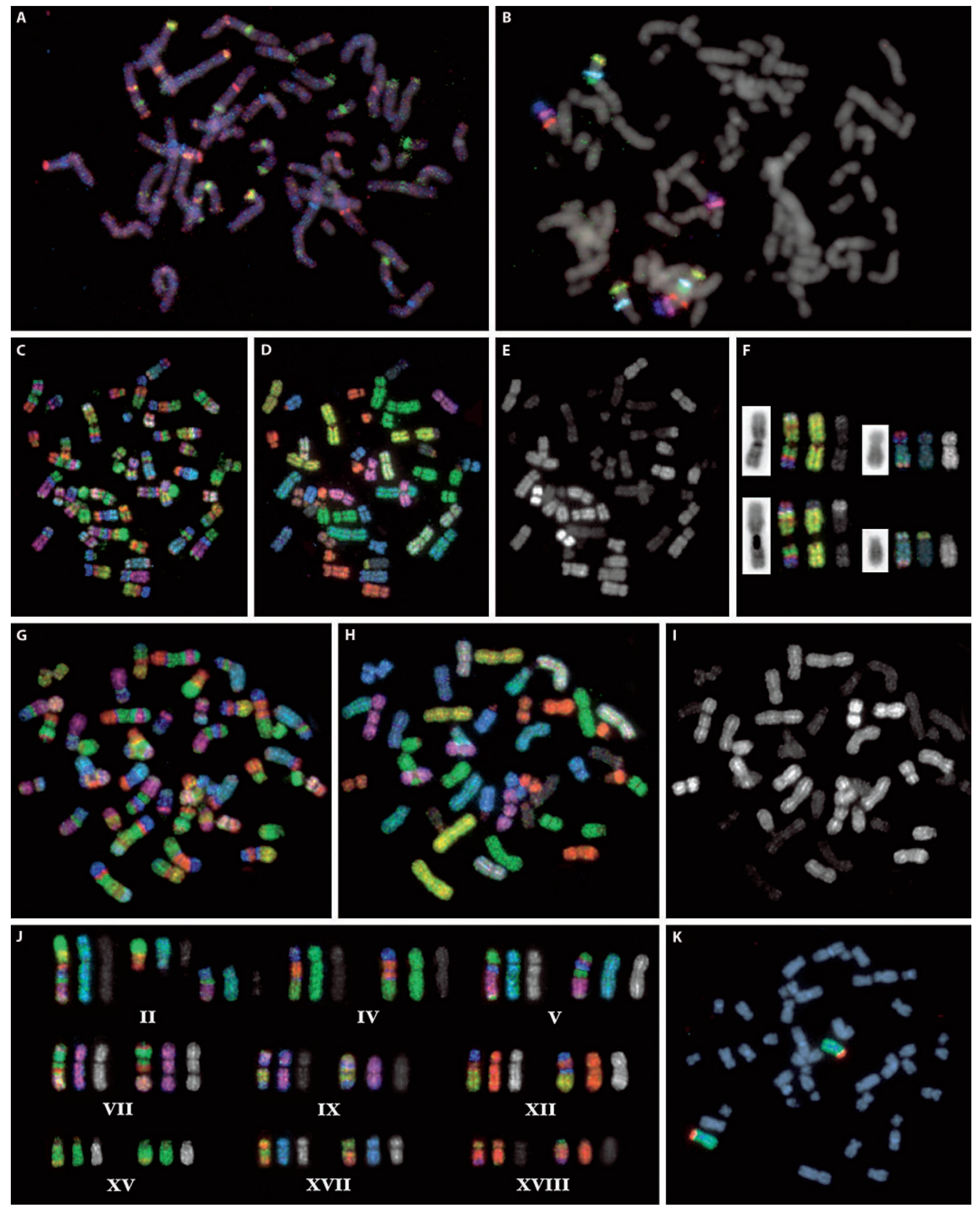


brids' were applied in a comparative molecular cytogenetic study of all great apes and the macaque (Müller and Wienberg, 2001). The objective of this study was to reconstruct the ancestral genome organization of hominoids using the macaque as outgroup species. The orangutan karyotype was found to have conserved a karyotype very similar to the proposed ancestral organization while African apes and human showed various derived changes. MCB was further used to delineate evolutionary chromosome rearrangements in chimpanzee, gorilla and a gibbon (Mrasek et al., 2001, 2003; Gross et al., 2006).

\section{Non-redundant chromosome bar codes}

A multicolor bar code would ideally provide a non-redundant color pattern that definitively allows the distinction of each bar, and thus the unequivocal identification of each tagged chromosome segment. The three bar coding approaches for screening of the entire karyotype that were described above do not fulfill this requirement and hence do not allow the unequivocal identification of all chromosome segments. This is due to a multitude of identically colored bars on different chromosomes. This limitation may be overcome by adding more color combinations or ratios to the probe labeling regime. Wiegant et al. (2000) extended the COBRA FISH technique to five fluorophores, thus increasing the number of differentially labeled probes to 48 . Using this strategy it was possible to differentially display all human chromosome arms in a single experiment and to screen for pericentric inversions in addition to translocations. The same group developed a BAC/PAC-based subtelomere COBRA FISH assay (S-COBRA FISH) for the detection of submicroscopic chromosomal rearrangements involving subtelomeric regions (Engels et al., 2003). Two hybridizations of 21 and 20 probes, respectively, were necessary for a complete analysis of all human chromosome ends except for $\mathrm{p}$-arms of acrocentrics.

Alternatively, color redundancy can be avoided when any given bar code probe set is complemented with a 24 color set of human whole chromosome painting probes in sequential hybridizations to the same slide (Müller et al., 2002). More recently, we developed bar code probes comprised of human whole chromosome and chromosome arm paint probes, of paint probes from non-human primates with evolutionary fragmented karyotypes, YACs and 'fragmented hybrids' (Müller et al., 2004). The combined probe set implemented seven different color planes of the same metaphase image and discriminated 100 regions of the human karyotype by a unique color code as outlined in Fig. 1C-F. This approach was successfully tested in a detailed karyotype analysis of four different tumor cell lines, several clinical cases (Fig. 1C-F) and a comparative study of the Pygmy chimpanzee (Bonobo, Pan paniscus, Fig. 1G-J) karyotype.

In recent years, however, new array-based approaches have been introduced that add to, or possibly even replace, some of the bar code based approaches. Most promising are techniques termed 'array CGH' (Greshock et al., 2004; Pinkel and Albertson, 2005 for recent reviews) and 'array painting' (Fiegler et al., 2003; Gribble et al., 2005). DNA copy number changes and chromosome breakpoints of translocations can now be analyzed at a resolution superior to molecular cytogenetic techniques.

\section{Conclusions}

We conclude that chromosome bar codes have the potential to span the bridge between chromosome painting for the identification of chromosome translocations and FISH of defined clones for the assignment of the breakpoints involved. An exciting perspective for future developments arise from the BAC resources made available by the human genome project. It is already possible to design tailor-made pools of BAC clones that cover a genomic region of any desired size and that are defined at the sequence level. These BAC pools provide robust FISH probes (Fig. $1 \mathrm{~K}$ ) which can be incorporated into multicolor chromosome bar codes. Such multiplex probes will add an entirely new level of precision to the definition of a chromosomal 'band' which will then be defined by its DNA sequence. Thus, bar codes will be useful tools at intermediate resolution between classical chromosome banding and high-resolution micro-array approaches.

\section{Acknowledgements}

We thank Nigel P. Carter, The Wellcome Trust Sanger Institute, Hinxton, UK, for providing DNA of the chromosome 6pter BAC pool and Udo Koehler, Medical Genetics Centre, Munich, Germany, for the patient chromosome sample. 


\section{References}

Chudoba I, Plesch A, Lorch T, Lemke J, Claussen U, Senger G: High resolution multicolor-banding: a new technique for refined FISH analysis of human chromosomes. Cytogenet Cell Genet 84:156-160 (1999).

Engels H, Ehrbrecht A, Zahn S, Bosse K, Vrolijk H, White S, Kalscheuer V, Hoovers JM, Schwanitz G, Propping P, Tanke HJ, Wiegant J, Raap AK: Comprehensive analysis of human subtelomeres with combined binary ratio labelling fluorescence in situ hybridisation. Eur J Hum Genet 11:643-651 (2003).

Espinet B, Sole F, Salido M, Lloveras E, Abella E, Besses C, Serrano S, Woessner S, Florensa L: Application of cross-species color banding ( $\mathrm{Rx}$ FISH) in the study of T- prolymphocytic leukemia. Haematologica 85:607-612 (2000).

Fiegler H, Gribble SM, Burford DC, Carr P, Prigmore E, Porter KM, Clegg S, Crolla JA, et al: Array painting: a method for the rapid analysis of aberrant chromosomes using DNA microarrays. J Med Genet 40:664-670 (2003).

Greshock J, Naylor TL, Margolin A, Diskin S, Cleaver SH, Futreal PA, de Jong PJ, Zhao S, Liebman M, Weber BL: 1-Mb resolution arraybased comparative genomic hybridization using a BAC clone set optimized for cancer gene analysis. Genome Res 14:179-187 (2004).

Gribble SM, Prigmore E, Burford DC, Porter KM, $\mathrm{Ng}$ BL, Douglas EJ, Fiegler H, Carr P, et al: The complex nature of constitutional de novo apparently balanced translocations in patients presenting with abnormal phenotypes. J Med Genet 42:8-16 (2005)

Gross M, Starke H, Trifonov V, Claussen U, Liehr T, Weiss A: A molecular cytogenetic study of chromosome evolution in chimpanzee. Cytogenet Genome Res 112:67-75 (2006).

Harrison CJ, Gibbons B, Yang F, Butler T, Cheung KL, Kearney L, Dirscherl L, Bray-Ward P, et al: Multiplex fluorescence in situ hybridization and cross species color banding of a case of chronic myeloid leukemia in blastic crisis with a complex Philadelphia translocation. Cancer Genet Cytogenet 116:105-110 (2000).

Harrison CJ, Yang F, Butler T, Cheung KL, O’Brien PC, Hennessy BJ, Prentice HG, Ferguson-Smith $\mathrm{M}$ : Cross-species color banding in ten cases of myeloid malignancies with complex karyotypes. Genes Chromosomes Cancer 30:15-24 (2001)

Henegariu O, Bray-Ward P, Artan S, Vance GH, Qumsyieh M, Ward DC: Small marker chromosome identification in metaphase and interphase using centromeric multiplex fish (CMFISH). Lab Invest 81:475-481 (2001a).
Henegariu O, Dunai J, Chen XN, Korenberg JR, Ward DC, Greally JM: A triple color FISH technique for mouse chromosome identification. Mamm Genome 12:462-465 (2001b).

Kim GJ, Park SY, Kim H, Chun YH, Park SH: Chromosomal aberrations in neuroblastoma cell lines identified by cross species color banding and chromosome painting. Cancer Genet Cytogenet 129:10-16 (2001).

Lengauer C, Speicher MR, Popp S, Jauch A, Taniwaki M, Nagaraja R, Riethman HC, DonisKeller H, et al: Chromosomal bar codes produced by multicolor fluorescence in situ hybridization with multiple YAC clones and whole chromosome painting probes. Hum Mol Genet 2:505-512 (1993).

Micci F, Teixeira MR, Dietrich CU, Saeter G, Bjerkehagen B, Heim S: Combined RxFISH/G banding allows refined karyotyping of solid tumors. Hum Genet 104:370-375 (1999).

Mrasek K, Heller A, Rubtsov N, Trifonov V, Starke H, Rocchi M, Claussen U, Liehr T: Reconstruction of the female Gorilla gorilla karyotype using 25-color FISH and multicolor banding (MCB). Cytogenet Cell Genet 93:242-248 (2001).

Mrasek K, Heller A, Rubtsov N, Trifonov V, Starke $\mathrm{H}$, Claussen U, Liehr T: Detailed Hylobates lar karyotype defined by 25 -color FISH and multicolor banding. Int J Mol Med 12:139-146 (2003).

Müller S, Wienberg J: Fortschritte bei der Entwicklung von chromosome bar codes: Integration von M-FISH und Rx-FISH Technologie. Med Gen 12:474-477 (2000).

Müller S, Wienberg J: 'Bar-coding' primate chromosomes: molecular cytogenetic screening for the ancestral hominoid karyotype. Hum Genet 109:85-94 (2001).

Müller S, Rocchi M, Ferguson-Smith MA, Wienberg J: Toward a multicolor chromosome bar code for the entire human karyotype by fluorescence in situ hybridization. Hum Genet 100 271-278 (1997)

Müller S, O’Brien PC, Ferguson-Smith MA, Wienberg J: Cross-species colour segmenting: a novel tool in human karyotype analysis. Cytometry 33:445-452 (1998).

Müller S, Neusser M, Wienberg J: Towards unlimited colors for fluorescence in-situ hybridization (FISH). Chromosome Res 10:223-232 (2002).
Müller S, Eder V, Wienberg J: A nonredundant multicolor bar code as a screening tool for rearrangements in neoplasia. Genes Chromosomes Cancer 39:59-70 (2004).

Nietzel A, Rocchi M, Starke H, Heller A, Fiedler W, Wlodarska I, Loncarevic IF, Beensen V, Claussen U, Liehr T: A new multicolor-FISH approach for the characterization of marker chromosomes: centromere-specific multicolor-FISH (cenM-FISH). Hum Genet 108:199_ 204 (2001).

Pinkel D, Albertson DG: Array comparative ge nomic hybridization and its applications in cancer. Nat Genet 37 Suppl: S11-17 (2005).

Ried T, Baldini A, Rand TC, Ward DC: Simultaneous visualization of seven different DNA probes by in situ hybridization using combinatorial fluorescence and digital imaging microscopy. Proc Natl Acad Sci USA 89:1388-1392 (1992).

Schröck E, du Manoir S, Veldman T, Schoell B, Wienberg J, Ferguson-Smith MA, Ning Y, Ledbetter $\mathrm{DH}$, et al: Multicolor spectral karyotyping of human chromosomes. Science 273:494497 (1996)

Sole F, Salido M, Espinet B, Garcia JL, Martinez Climent JA, Granada I, Hernandez JM, Benet I, et al: Splenic marginal zone B-cell lymphomas: two cytogenetic subtypes, one with gain of $3 q$ and the other with loss of 7q. Haematologica 86: 71-77 (2001)

Speicher MR, Gwyn Ballard S, Ward DC: Karyotyping human chromosomes by combinatorial multi-fluor FISH. Nat Genet 12:368-375 (1996).

Tanke HJ, Wiegant J, van Gijlswijk RP, Bezrookove V, Pattenier H, Heetebrij RJ, Talman EG, Raap AK, Vrolijk J: New strategy for multi-colour fluorescence in situ hybridisation: COBRA: COmbined Binary RAtio labelling. Eur J Hum Genet 7:2-11 (1999).

Weise A, Heller A, Starke H, Mrasek K, Kuechler A Pool-Zobel BL, Claussen U, Liehr T: Multitude multicolor chromosome banding (mMCB) - a comprehensive one-step multicolor FISH banding method. Cytogenet Genome Res 103:34-39 (2003).

Wiegant J, Bezrookove V, Rosenberg C, Tanke HJ, Raap AK, Zhang H, Bittner M, Trent JM, Meltzer P: Differentially painting human chromosome arms with combined binary ratio-labeling fluorescence in situ hybridization. Genome Res 10:861-865 (2000) 